\title{
The mechanisms and treatment of asphyxial encephalopathy
}

\author{
Guido Wassink, Eleanor R. Gunn, Paul P. Drury, Laura Bennet and Alistair J. Gunn*
}

Fetal Physiology and Neuroscience Team, Department of Physiology, Faculty of Medical and Health Sciences, University of Auckland, Auckland, New Zealand

\section{Edited by:}

Mario Herrera-Marschitz, University of Chile, Chile

Reviewed by:

Guanglong Jiang, Capital Normal University, China

Bibhash Mukhopadhyay, Johnson \& Johnson, USA

*Correspondence:

Alistair J. Gunn, Fetal Physiology and Neuroscience Team,

Department of Physiology, Faculty of Medical and Health Sciences, University of Auckland, Private Bag 92019, Auckland, New Zealand e-mail:aj.gunn@auckland.ac.nz
Acute post-asphyxial encephalopathy occurring around the time of birth remains a major cause of death and disability. The recent seminal insight that allows active neuroprotective treatment is that even after profound asphyxia (the "primary" phase), many brain cells show initial recovery from the insult during a short "latent" phase, typically lasting approximately $6 \mathrm{~h}$, only to die hours to days later after a "secondary" deterioration characterized by seizures, cytotoxic edema, and progressive failure of cerebral oxidative metabolism. Although many of these secondary processes are potentially injurious, they appear to be primarily epiphenomena of the "execution" phase of cell death. Animal and human studies designed around this conceptual framework have shown that moderate cerebral hypothermia initiated as early as possible but before the onset of secondary deterioration, and continued for a sufficient duration to allow the secondary deterioration to resolve, has been associated with potent, long-lasting neuroprotection. Recent clinical trials show that while therapeutic hypothermia significantly reduces morbidity and mortality, many babies still die or survive with disabilities. The challenge for the future is to find ways of improving the effectiveness of treatment. In this review, we will dissect the known mechanisms of hypoxic-ischemic brain injury in relation to the known effects of hypothermic neuroprotection.

Keywords: asphyxia, encephalopathy, hypothermia, neuroprotection, injury

\section{INTRODUCTION}

Moderate to severe neonatal hypoxic-ischemic encephalopathy occurs in approximately $1-3$ cases per 1000 term live births in developed nations (Kurinczuk et al., 2010), and remains a significant cause of death and long-term neurodevelopmental disability (Lawn et al., 2005; Marlow et al., 2005). The most devastating complication in survivors is cerebral palsy, which is associated with one of the very highest indices of burden of disease from loss of potential productive members of society and direct burdens on the individual, family, and social institutions that last the entire life (Centers for Disease Control and Prevention (CDC), 2004). Approximately $15 \%$ of all cases of cerebral palsy are associated with acute brain damage (encephalopathy) in term infants (Mcintyre et al., 2011).

There is now compelling clinical evidence from meta-analyses of large randomized controlled trials that prolonged moderate cerebral hypothermia in term infants with moderate to severe hypoxic-ischemic encephalopathy, started within a few hours after birth and continued until resolution of the acute phase of delayed cell death improves neurodevelopmental outcome in the medium to long-term (Edwards et al., 2010; Guillet et al., 2012; Shankaran et al., 2012b). This functional improvement is consistent with reduced brain injury on modern imaging (Rutherford et al., 2010; Shankaran et al., 2012a). Hypothermia suppresses many potentially deleterious mechanisms, making it difficult to distinguish between physiological changes during cooling that are critically beneficial, compared with those that are either indifferent or even deleterious.
Current therapeutic hypothermia protocols are incompletely neuroprotective, reducing the combined risk of death and severe disability at 18 months of age by approximately $11 \%$ (Edwards et al., 2010). Thus, many children continue to die, or survive with moderate to severe handicap despite treatment with current hypothermia protocols. Expanding our knowledge of the key therapeutic targets of hypothermia could help to further improve existing protection. In the present review we will critically assess the potential mechanisms of hypothermic neuroprotection in relation to the known window of opportunity for cooling after severe hypoxia-ischemia (HI).

\section{THE EVOLUTION OF HYPOXIC-ISCHEMIC INJURY}

The central insight that underpinned development of therapeutic hypothermia was that $\mathrm{HI}$ injury evolves over time, as illustrated in Figure 1 (Gunn and Thoresen, 2006). We now know that although some neurons likely die during the actual ischemic or asphyxial event (the "primary" phase of injury, Figures 1, 2), the hypoxia-induced impairment of cerebral oxidative metabolism, cytotoxic edema, and accumulation of excitatory amino acids (EAAs) typically recovers at least partially over approximately 30 60 min (Tan et al., 1996; Bennet et al., 2007b). This is followed by a "latent" phase during which electroencephalogram (EEG) activity remains suppressed but high energy phosphates are normal or near normal (Azzopardi et al., 1989; Gunn et al., 1997; Bennet et al., 2006; Iwata et al., 2008). Notably, during this phase there is post-asphyxial cerebral hypoperfusion associated with reduced cerebral metabolism and improved tissue oxygenation in 


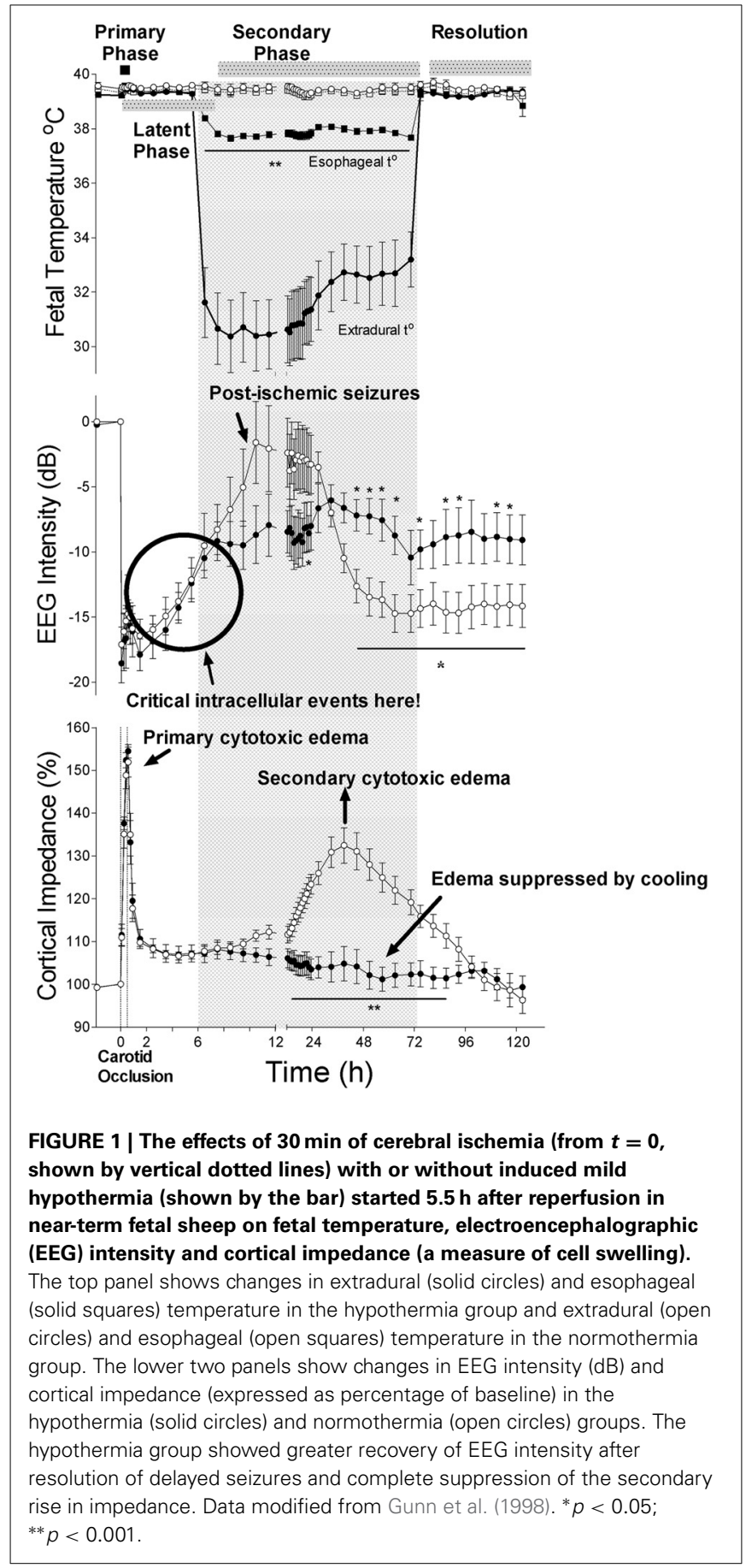

the near-term lamb (Jensen et al., 2006), consistent with active suppression of cerebral metabolism.

With moderate to severe injury, this period is frequently followed by progressive secondary deterioration many hours later (from approximately 6-15 h), that is typically associated with stereotypic seizures (Gunn et al., 1997), cytotoxic edema and accumulation of excitotoxins, near-complete failure of cerebral mitochondrial activity (Lorek et al., 1994; Bennet et al., 2006) and eventual spreading cell death. More severe insults are typically

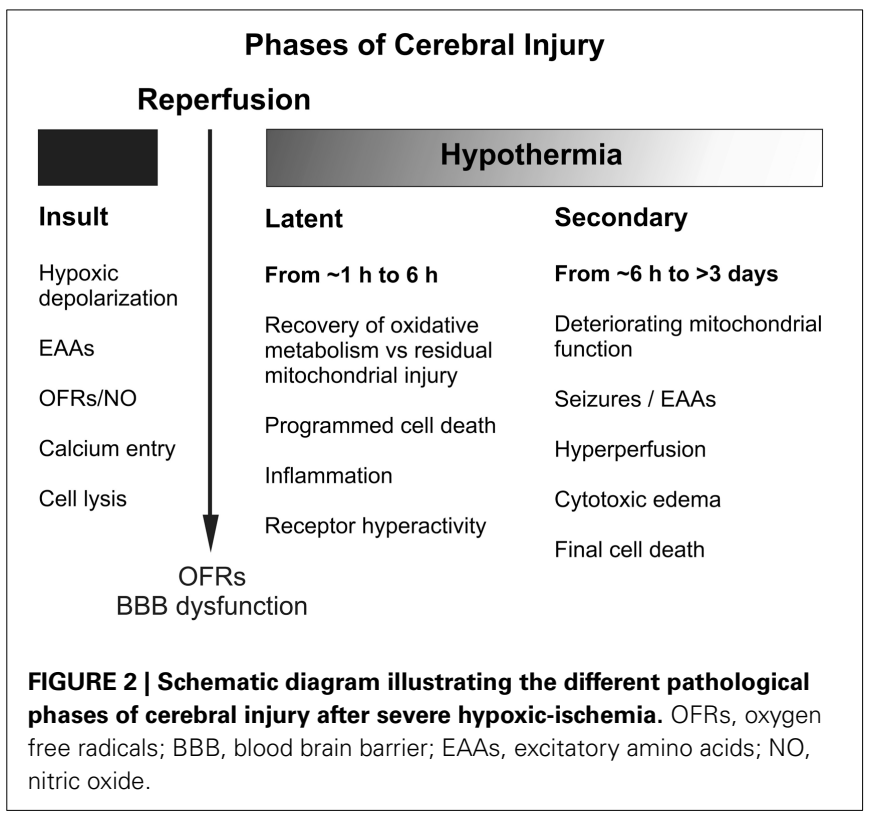

associated with evidence of greater primary damage (Williams et al., 1992), and earlier and more severe secondary deterioration and neuronal loss (Williams et al., 1992; Lorek et al., 1994; Sabir et al., 2012). In turn, the severity of secondary oxidative metabolism derangement in newborns with birth asphyxia is strongly associated with increased risk of mortality and adverse neurodevelopmental outcome (Roth et al., 1992).

\section{MECHANISMS OF INJURY DURING HYPOXIA-ISCHEMIA}

Brain injury requires a period of insufficient delivery of oxygen and substrates such as glucose (and lactate in the fetus) such that neurons and glia cannot maintain homeostasis. Once the neuron's supply of high-energy metabolites such as adenosine triphosphate (ATP) can no longer be maintained during $\mathrm{HI}$, the energy dependent mechanisms of intracellular homeostasis including the $\mathrm{Na}^{+} / \mathrm{K}^{+}$ATP dependent pump begin to fail. Neuronal depolarization occurs, leading to sodium and calcium entry into cells. This creates an osmotic and electrochemical gradient that in turn favors further cation and water entry leading to cell swelling (cytotoxic edema). Consequently, this may lead to acute cell lysis when the homeostatic disturbance is sufficiently severe (Rothman and Olney, 1995). Even after surprisingly prolonged and severe insults, however, many swollen neurons still recover, at least temporarily, if the hypoxic insult is reversed or the osmotic environment is manipulated. Evidence suggests that several additional factors act to increase cell injury during and following depolarization. One of these factors is the extracellular accumulation of EAAs after neuronal depolarization coupled with impaired energy dependent re-uptake, which promote further receptor mediated cell swelling and intracellular calcium entry (Rothman and Olney, 1995). Another factor is the generation of oxygen free radicals such as the highly toxic hydroxyl radical $(\cdot \mathrm{OH})$, leading to lipid peroxidation and DNA/RNA fragmentation (Bagenholm et al., 1998; Fraser et al., 2008). Further, there is compelling evidence that generation of the reactive oxygen species 
nitric oxide (NO*) by neuronal nitric oxide synthase (nNOS) is increased during and after $\mathrm{HI}$, and that reaction of $\mathrm{NO} \cdot$ with superoxide in the cytosol and mitochondria produces peroxynitrite and other reactive nitrogen species that are associated with cell membrane, organelle and mitochondrial damage (Tan et al., 1999). For example, selective nNOS blockade during asphyxia reduced neuronal damage in the basal ganglia of preterm fetal sheep (Drury et al., 2013). However, these factors largely appear to be injurious only in the presence of hypoxic cell depolarization.

\section{HYPOTHERMIA DURING HYPOXIA-ISCHEMIA}

Hypothermia produces a reduction in cerebral metabolism of approximately $5 \%$ for every 1 degree fall in temperature (Laptook et al., 1995), which delays the onset of anoxic cell depolarization. The protective effects of hypothermia are not simply due to reduced metabolism alone, however, since graded cooling substantially reduces damage for a given absolute duration of depolarization compared to normothermia (Bart et al., 1998). The reduced accumulation of EAAs during intra-ischemic hypothermia (Nakashima and Todd, 1996a; Ooboshi et al., 2000), is primarily due to delay in depolarization, although there is some evidence for a reduction in the rate of release even after depolarization has occurred (Nakashima and Todd, 1996b). In addition, hypothermia potently suppresses NO* and superoxide formation in hippocampal slice cultures (Mcmanus et al., 2004), during ischemia and reperfusion in rodents (Lei et al., 1997), cardiac arrest in young adult dogs (Lei et al., 1994), and during and immediately after HI in the piglet (Thoresen et al., 1997).

\section{HYPOTHERMIA DURING REPERFUSION}

Once blood flow and oxygenation are restored after acute HI, there is a rapid burst of NO' and superoxide formation (Thoresen et al., 1997), and EAA levels rapidly fall in parallel with resolution of the acute cell swelling, typically over 30-60 min (Tan et al., 1996; Fraser et al., 2008). It would appear that this recovery can be accelerated by cooling; hypothermia started immediately after $\mathrm{HI}$ in newborn piglets was associated with reduced extracellular levels of EAAs, and reduced NO* efflux in the brain (Thoresen et al., 1997).

\section{HYPOTHERMIA AND THE BLOOD BRAIN BARRIER}

Ischemic brain injury is generally associated with marked opening of the blood brain barrier (BBB) which may contribute to further brain swelling. In adult rats, cooling after global ischemia was associated with reduced BBB leakiness and brain edema $24 \mathrm{~h}$ later, but only when induced within $1 \mathrm{~h}$ after ischemia (Preston and Webster, 2004; Baumann et al., 2009). Such stabilization of the BBB by hypothermia was associated with attenuated degradation of key regulatory proteins in the vascular basement membrane (Baumann et al., 2009). Similarly, hypothermia induced $1 \mathrm{~h}$ after focal ischemia in rats was associated with improved BBB function, possibly by inhibiting metalloproteinase induction (Nagel et al., 2008). However, the inhibition of metalloproteinases after $\mathrm{HI}$ in neonatal rats has had inconsistent effects (Ranasinghe et al., 2012). Given that treatment with hypothermia is highly neuroprotective even when delayed by more than an hour after $\mathrm{HI}$ (Gunn et al., 1997, 1998; Colbourne et al., 2000; Sabir et al., 2012), it seems unlikely that this mechanism is a major contributor to hypothermia's beneficial effects.

\section{CRITICAL CLUES FROM STUDIES OF HYPOTHERMIA DURING THE LATENT PHASE}

Although it remains unclear when exactly the brain becomes irreversibly injured, there are consistent empirical data that the so-called "latent" or early recovery phase of transient restoration of cerebral oxidative metabolism, before onset of secondary energy failure, represents the most realistic window of opportunity for therapeutic intervention (Roelfsema et al., 2004; Gunn and Gluckman, 2007). Thus, pragmatically, the window of intervention appears to close indefinitely during secondary energy failure, which corresponds either to overt cell death (Vannucci et al., 2004), or to a critical "irreversible" stage in the evolution of delayed cell death (Gunn and Gluckman, 2007).

For example, in the near-term fetal sheep, moderate hypothermia induced $90 \mathrm{~min}$ after reperfusion from a severe episode of cerebral ischemia (i.e., in the early latent phase) and continued until $72 \mathrm{~h}$ after ischemia, prevented secondary cytotoxic edema, improved electroencephalographic recovery, and reduced neuronal and white matter injury (Gunn et al., 1997; Roelfsema et al., 2004). However, only partial protection was seen in this paradigm when hypothermia was delayed until just before the onset of secondary seizures ( $5.5 \mathrm{~h}$ after reperfusion, e.g. see Figure 1) (Gunn et al., 1998; Roelfsema et al., 2004), and there was no significant protection when the start of cooling was delayed until after seizures were established ( $8.5 \mathrm{~h}$ after reperfusion) (Gunn et al., 1999).

These observations are consistent with previous studies in anaesthetized piglets subjected to severe HI, where application of prolonged moderate to deep hypothermia for $24 \mathrm{~h}$ immediately after resuscitation prevented secondary energy failure, suppressed seizure burden, and reduced neural loss in the cortex and basal ganglia (Edwards et al., 1995; Thoresen et al., 1995; Tooley et al., 2003). Similar progressive loss of neuroprotection was found when $5 \mathrm{~h}$ of moderate hypothermia was delayed for up to $6 \mathrm{~h}$ after moderate $\mathrm{HI}$ in postnatal day 7 rat pups (Sabir et al., 2012), while this relatively short period of hypothermia was not protective at all after a more severe insult. Studies in adult rodents strongly suggest that more prolonged cooling, for $48 \mathrm{~h}$ or more, further improves the effect of delayed cooling (Colbourne et al., 1999a); it remains unclear whether there would be further benefit if cooling was continued for longer than approximately $48-72 \mathrm{~h}$.

\section{EVOLUTION OF INJURY DURING THE LATENT PHASE}

The precise mechanism(s) which initiate the cascade leading to delayed cell death after HI remain incompletely understood, but are undoubtedly multi-factorial with excessive calcium influx, pro- and anti-apoptotic proteins, and trophic factor withdrawal during and after HI all playing a critical role (Zipfel et al., 2000; Hagberg et al., 2009). For example, neural accumulation of calcium precipitates continues for many hours after $\mathrm{HI}$ in the immature rodent (Stein and Vannucci, 1988), and is associated with worsening structural morphology (Puka-Sundvall et al., 2000). Although mitochondria can buffer increased levels of neuronal 
cytosolic calcium (Wang and Thayer, 1996), excessive sequestration of calcium by mitochondria may lead to inhibition of the respiratory chain, uncoupling of oxidative phosphorylation (Szydlowska and Tymianski, 2010), and permeabilization of the mitochondrial membranes (the "intrinsic" apoptosis pathway).

In detail, HI results in activation of pro- and anti-apoptotic proteins (Hagberg et al., 2009), and translocation of cytosolic Bcl-2 associated $\times$ protein $(\mathrm{Bax})$ to mitochondria (Rousset et al., 2012), where it oligomerizes (with Bcl-2 family members Bak and Bid) and creates non-specific protein pores in the outer mitochondrial membrane. This allows leakage of pro-apoptotic proteins and cytochrome c into the cytosol (Figure 3) (Hagberg et al., 2009). Not only are pro- and anti-apoptotic proteins and caspase-3 highly expressed in the immature brain (Polster et al., 2003; Zhu et al., 2005; Soane et al., 2008), but regulating their interaction can provide significant neuroprotection after perinatal HI (Gibson et al., 2001; Wang et al., 2010; Nijboer et al., 2011). As the terminal electron acceptor of the mitochondrial electron transport chain, loss of cytochrome $c$ oxidase may be particularly decisive in the uncoupling of oxidative phosphorylation, since it accounts for over 90\% of cellular oxygen consumption (Cooper and Springett, 1997). Thus, the permeabilization of mitochondrial membranes, with detachment of soluble protein cytochrome $\mathrm{c}$ from cardiolipin on the inner mitochondrial membrane (Hagberg et al., 2009), and release of apoptogenic factors including second mitochondria-derived activator of caspase (Smac), direct inhibitor of apoptosis binding protein with low Pi (Diablo) and apoptosis inducing factor (AIF) from the mitochondrial intermembrane space (Martinou and Green, 2001), could shift a potentially reversible injurious paradigm to irrevocable cell death.

After its release cytosolic cytochrome $\mathrm{c}$ binds to apoptotic protease-activating factor-1 (Apaf-1), and activates caspase 9 in the presence of ATP or dATP to form an apoptosome, which initiates the executioner caspase-3 (Martinou and Green, 2001), and ultimately leads to DNA fragmentation (Figure 3). This functional decline of mitochondria appears to be consistent with the progressive fall in cytochrome oxidase seen from $3 \mathrm{~h}$ onwards after asphyxia in fetal sheep (Bennet et al., 2010), before onset of secondary cytotoxic edema and stereotypic seizures. Critically, one kinetic study using HeLa cell lines showed that, after initiation of cytochrome c release, all cytochrome $\mathrm{c}$ was invariably released from mitochondria within $5 \mathrm{~min}$, and this release preceded the apoptotic cascade (Goldstein et al., 2000). There is good histological evidence that programmed cell death is a significant contributor to post-hypoxic cell death in the developing human brain (Edwards et al., 1997; Scott and Hegyi, 1997). Additional factors that likely help trigger or augment programmed cell death include loss of trophic support from astrocytic growth factors (Clawson et al., 1999), and the inflammatory reaction to HI (Giulian and Vaca, 1993), through activation of cell surface death receptors (and thus the "extrinsic" apoptosis pathway; Graham et al., 2004). The delayed increase in synthesis of down-stream mediators of cell death such as NO and reactive oxygen species in this phase are likely secondary to inflammation (Gehrmann et al., 1995). In addition, recent data indicate that "extrinsic" TNF and Fas death receptor engagement can also promote cross-over activation of the "intrinsic" apoptotic pathway through association with the pro-apoptotic tBid protein on Bak and Bax (Figure 3) (Wei et al., 2001; Schug et al., 2011).

\section{DOES HYPOTHERMIA SPECIFICALLY SUPPRESS DELAYED PROGRAMMED CELL DEATH?}

There is evidence that hypothermia may have a particular role in suppressing the evolution of programmed cell death. Studies using morphological criteria have had mixed outcomes. In the piglet, hypothermia started after severe HI was reported to reduce apoptotic cell death, but not necrotic cell death (Edwards et al., 1995), with similar results reported after injury in rats (Xu et al., 1998; Inamasu et al., 2000). However, in the adult rat, delayed post-ischemic cell death prevented by hypothermia had a necrotic appearance on detailed electron microscopic criteria (Colbourne et al., 1999b), consistent with findings of a maturity related reduction in cytochrome $\mathrm{c}$ release, AIF and caspase- 3 expression after $\mathrm{HI}$ in rodents (Hu et al., 2000; Zhu et al., 2005).

It is important to appreciate that in practice these morphological changes often do not closely reflect the underlying pathways leading to cell death. By analogy with the active process of developmental "pruning" of excess cells (including neurons), it was originally suggested that an apoptotic morphology reflected activation of "pre-programmed" cell death pathways (Beilharz et al., 1995; Dell'anna et al., 1997). Although necrosis can reflect immediate biophysical damage to the cell, such as membrane instability or ion shifts leading to cell lysis in the primary phase (Beilharz et al., 1995), there is now compelling evidence that post-hypoxic cell death represents a continuum between apoptosis and necrosis, as recently reviewed (Northington et al., 2011). In vitro, hypothermia during severe hypoxia reduced both "apoptotic" and "necrotic" morphological cell death in developing rat neurons, and suppressed hypoxia-associated protein synthesis (Bossenmeyer-Pourie et al., 2000). Microarray analysis in rats after focal ischemia confirmed that post-insult hypothermia suppressed gene responses to ischemia, particularly genes involved in calcium homeostasis, cellular and synaptic integrity, inflammation, cell death, and apoptosis (Nagel et al., 2012).

Although there are multiple pathways to programmed cell death, as discussed above, caspase- 3 is the final "executioner" caspase, and thus caspase- 3 activation may be used as a reasonable marker of these pathways. Other in vitro studies have shown that mild hypothermia suppressed $\mathrm{H}_{2} \mathrm{O}_{2}$-induced apoptosis and caspase-3 induction in rat cortical neurons (Li et al., 2012), and suppressed neuronal apoptosis induced by serum deprivation, with significantly reduced activation of caspases -3, -8, and 9 after $24 \mathrm{~h}$, and reduced cytochrome c translocation consistent with suppression of both the intrinsic and extrinsic pathways of apoptosis (Xu et al., 2002). Further, hypothermia during focal ischemia in adult rats reduced expression of the cell death receptor Fas and activation of caspase-8, supporting a direct effect on the extrinsic pathway of apoptosis (Liu et al., 2008).

These studies examined forms of intra-insult cooling. However, there is supporting evidence from post-insult cooling in vivo. For example, in the near-term fetal sheep, hypothermia delayed for $90 \mathrm{~min}$ after ischemia markedly suppressed caspase-3 activation in white matter (Roelfsema et al., 2004). Similarly, in postnatal day 7 (P7) rats, an age when brain development is comparable to the late preterm human infant (Rice et al., 1981), 


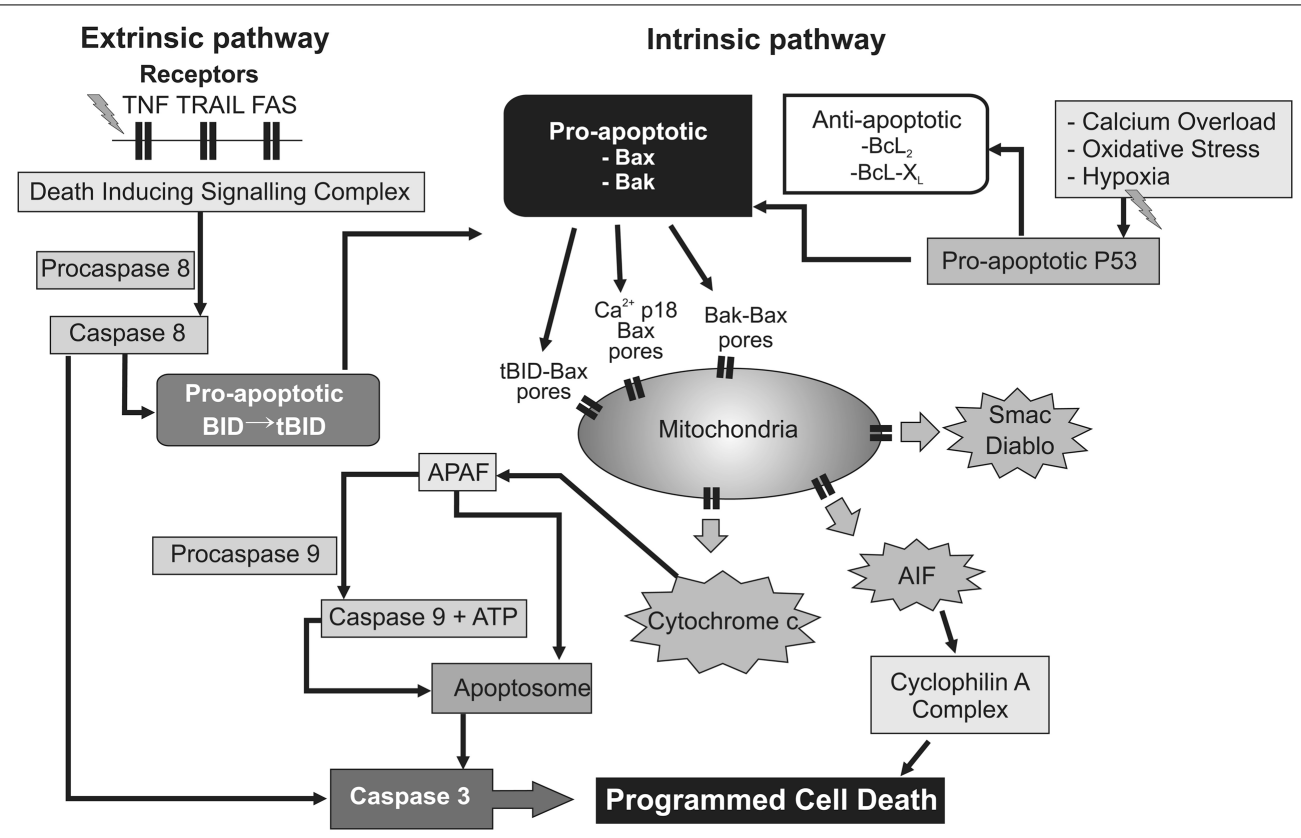

FIGURE 3 | Flow chart depicting several intracellular mechanisms associated with permeabilization of the mitochondrial membranes, leading to progressive failure of mitochondrial oxidative phosphorylation and ultimately delayed programmed cell death. Upstream triggers such as inflammation and trophic withdrawal activate cell surface death receptors initiating the "extrinsic" pathway to programmed cell death. Conversely, calcium overload and oxygen free radicals appear to exert their effect predominantly at the mitochondrial level via the "intrinsic" pathway. In addition, cross-over activation between the "extrinsic" and "intrinsic" pathway may take place through pro-apoptotic intermediates such as the BID protein. AIF, apoptosis inducing factor. Apaf-1, apoptotic protease-activating factor-1; ATP, adenosine triphosphate; $\mathrm{BAK}, \mathrm{Bcl}_{2}$-antagonist/killer 1; $\mathrm{BAX}$,

$\mathrm{BCl}_{2}$-associated $\times$ protein; $\mathrm{BCl}_{2}$, B-cell lymphoma 2 protein family; $\mathrm{BCl}-\mathrm{X}_{\mathrm{L}}$, B-cell lymphoma-extra-large; $\mathrm{BID}, \mathrm{BH} 3$ interacting-domain death agonist; Diablo, direct inhibitor of apoptosis binding protein with low Pi; P53, p53 tumor suppressor protein; Smac, Second mitochondria-derived activator of caspase; tBID, truncated $\mathrm{BH} 3$ interacting-domain death agonist; TNF, tumor necrosis factor receptor; TRAIL, TNF-related apoptosis-inducing ligand receptor. immediate induction of hypothermia after HI reduced caspase3 expression in the core area of cortical infarction but not in the penumbra (Askalan et al., 2011), suggesting that hypothermia modulated both caspase-dependent and independent mechanisms. In the same paradigm, hypothermia also reduced caspase3 activation in pre-oligodendrocytes (Xiong et al., 2013). In adult rats, mild hypothermia $\left(33^{\circ} \mathrm{C}\right)$ for $2 \mathrm{~h}$ after transient endothelin-induced focal ischemia suppressed activated caspase3 immunoreactivity up to a week after the insult (Zgavc et al., 2013). Similarly, hypothermic neuroprotection after transient global ischemia in adult rats was associated with upregulation of the anti-apoptotic protein bcl-2, and reduced expression of the pro-apoptotic protein p53 (Zhang et al., 2010).

There is some evidence from adult models that hypothermia can specifically suppress the mitochondrial permeability transition. For example, mild hypothermia either during or shortly after transient focal ischemia attenuated the release of cytochrome c (Yenari et al., 2002; Zhao et al., 2004). Similarly, protection of the CA1 region of the hippocampus with mild hypothermia after global ischemia was associated with reduced cytochrome c release after $48 \mathrm{~h}$, and with reduced caspase- 3 and -9 activity at 12 and $24 \mathrm{~h}$ (Zhao et al., 2005). Further, neuroprotection with immediate, prolonged cooling after cardiac arrest in adult minipigs was associated with suppression of mitochondrial permeability pore opening, leading to reduced release of cytochrome $\mathrm{c}$ and other pro-apoptotic factors including AIF and reduced caspase-3 activation (Gong et al., 2013). Post-ischemic hypothermia maintained mitochondrial respiratory activity $2 \mathrm{~h}$ after reperfusion in the adult gerbil (Canevari et al., 1999), and intra-ischemic hypothermia has been shown to preserve activity for 4 days after a similar insult in neonatal rats (Nakai et al., 2001). Presently, there are no data evaluating mitochondrial function in vivo during therapeutic hypothermia following $\mathrm{HI}$ in the developing brain. However, hypothermia after cardiac arrest in adult minipigs substantially improved recovery of mitochondrial membrane potential and respiration (Gong et al., 2013).

Finally, there is evidence that combined treatment with the anti-apoptotic agent, insulin-like growth factor 1 (Guan et al., 2001), and hypothermia starting $4.5 \mathrm{~h}$ after cerebral ischemia in near-term fetal sheep did not show additive neuroprotection (George et al., 2011). This observation suggests that their mechanisms of action overlap. Taken as a whole, these studies indicate that hypothermia can suppress apoptosis, likely through several pathways including reduction of mitochondrial permeability (the intrinsic pathway) and reduced activation of the extrinsic pathway of apoptosis.

\section{HYPOTHERMIA AND INFLAMMATORY SECOND MESSENGERS}

Brain injury leads to induction of the inflammatory cascade with increased release of cytokines and interleukins (IL) (Hagberg 
et al., 2012). These compounds are believed to exacerbate delayed injury, whether by direct neurotoxicity and induction of apoptosis or by promoting leukocyte diapedesis into the ischemic brain. Experimentally, cooling potently suppresses this inflammatory reaction (Roelfsema et al., 2004). For example, in vitro, hypothermia inhibits microglia proliferation, chemotaxis, induction of pro-inflammatory cytokines, and attenuates microglia neurotoxicity, during and critically, after exposure to both hypoxia and lipopolysaccharide (Si et al., 1997; Schmitt et al., 2007; Seo et al., 2012). Further, hypothermia can suppress translocation and binding of nuclear factor kappa-B, a key inflammatory transcription factor that is activated after cerebral ischemia (Yenari and Han, 2006). In addition, there is limited evidence that cooling microglia after activation with lipopolysaccharide increases production of anti-inflammatory cytokines in culture (Diestel et al., 2010).

Consistent with these in vitro findings, hypothermia in adult rats after transient focal ischemia reduced delayed increases in interleukin-1 $\beta$ (IL-1 $\beta$ ) and tumor necrosis factor alpha (TNF- $\alpha$ ) but not transforming growth factor beta (TGF- $\beta$ ) in the striatum (Ceulemans et al., 2011). In adult pigs, immediate mild cooling after brief cardiac arrest was associated with attenuation of IL-1 $\beta$, TNF- $\alpha$, intercellular adhesion molecule- 1 mRNA, and interleukin-1 (IL-1) protein induction $24 \mathrm{~h}$ after resuscitation (Meybohm et al., 2010). Similarly, post-insult hypothermia has been associated with consistent suppression of activated microglia after transient ischemia or asphyxia in fetal sheep (Roelfsema et al., 2004; Bennet et al., 2007c; Barrett et al., 2012; George et al., 2012). This broad reduction in inflammatory signaling may offer significant mitochondrial protection. For example, cytokine mediated iNOS expression increases NO• levels, which compete with molecular oxygen at its binding site on cytochrome oxidase (Brown, 1997), potently suppressing oxidative metabolism and thus reducing ATP levels (Tatsumi et al., 2000). Furthermore, TNF- $\alpha$ and interferon- $\gamma$ mediated iNOS expression were associated with mitochondrial DNA damage and apoptosis in cultured oligodendrocytes (Druzhyna et al., 2005).

Intriguingly, despite the potent suppression of microglia by hypothermia, it has little effect on astrocytic proliferation in vitro (Si et al., 1997). This raises the possibility that hypothermic protection against post-ischemic neuronal damage may be, in part, the result of differential effects on glia, with suppression of microglial activation but relative sparing of potentially pro-survival astrocytic reactions.

\section{HYPOTHERMIA AND EXCITOTOXICITY}

In contrast to their role during the primary and reperfusion phases, the importance of excitotoxins after reperfusion remains surprisingly unclear, given that extracellular levels rapidly return to baseline values (Tan et al., 1996; Thoresen et al., 1997). The apparent protection seen in early studies of anti-excitotoxic agents is difficult to interpret as these studies did not control for cerebral temperature (Mcdonald et al., 1987; Hattori et al., 1989). Indeed, subsequent studies suggested that the effects of glutamate blockade during HI were either largely or synergistically mediated through drug-induced hypothermia (Ikonomidou et al., 1989; Engidawork et al., 2001). In an elegant study in the adult rat,
Nurse and Corbett showed that the apparent neuroprotective effect of NBQX, a glutamate antagonist administered from $1 \mathrm{~h}$ after mild cerebral ischemia, was directly associated with mild endogenous hypothermia for several days that developed an hour after drug administration (Nurse and Corbett, 1996). Strikingly, similar neuroprotection was induced by application of the same hypothermia profile over $28 \mathrm{~h}$, while conversely NBQX "neuroprotection" was abolished by maintaining normothermia. Furthermore, anti-excitotoxin therapy limited to the secondary phase did not reduce neuronal injury in the severely injured parasagittal cortex of fetal sheep, and had only limited neuroprotective effects in more mildly affected areas of the brain (Tan et al., 1992; Gressens et al., 2011).

Nevertheless, even with normal levels of extracellular glutamate, excitotoxicity may still play an indirect injurious role. Pathological hyperexcitability of glutamate receptors has been reported in P10 rats for many hours after HI, with improved neuronal outcome after receptor blockade (Jensen et al., 1998). Further, neuronal death after ischemia has been associated with a selective, delayed change in the composition of the alpha-amino3-hydroxy-5-methyl-4-isoxazolepropionic acid (AMPA) receptor, with specific down-regulation of GluR2, the subunit that limits $\mathrm{Ca}^{2+}$ influx through the AMPA receptor. This may facilitate further excessive influx of $\mathrm{Ca}^{2+}$ during spontaneous glutaminergic activity after HI, thus promoting programmed cell death. In adult gerbils, delayed hypothermia from $20 \mathrm{~min}$ after global ischemia attenuated these changes in the GluR2 subunit, providing an additional possible mechanism for indirect protection from excessive excitation (Colbourne et al., 2003).

Supporting this hypothesis, despite suppression of overall EEG activity for many hours after asphyxia, transient epileptiform activity was seen in the early recovery phase in preterm sheep fetuses that developed severe injury (George et al., 2004), and was correlated with the severity of neuronal loss in the striatum and hippocampus (Dean et al., 2006b; Bennet et al., 2007c). Suppression of these EEG transients with a glutamate receptor antagonist partially reduced cell loss (Dean et al., 2006a). Furthermore, neuroprotection with post-asphyxial moderate cerebral hypothermia in the preterm fetal sheep was associated with a marked reduction in numbers of epileptiform transients in the first $6 \mathrm{~h}$ after asphyxia, and reduced amplitude but not numbers of delayed seizures (Bennet et al., 2007a). The combination of glutamate receptor antagonist infusion and hypothermia after severe asphyxia in preterm fetal sheep, however, showed non-additive neuroprotection, consistent with the suggestion that therapeutic hypothermia is partly protective by attenuating this receptor hyperactivity (George et al., 2012). Further studies are needed to determine whether this is also the case after hypoxic-ischemic injury in the term-equivalent brain.

\section{HYPOTHERMIA AND INDUCTION OF GROWTH FACTORS}

Contrary to the assumption that hypothermia generally suppresses new protein synthesis, there is evidence in the adult rat that mild hypothermia after cardiac arrest or ischemia is associated with augmentation of growth factors such as brain-derived neurotrophic factor (BDNF), glial-cell-line derived neurotrophic factor and extracellular-signal regulated kinase 
(D'Cruz et al., 2002; Schmidt et al., 2003; Kim et al., 2011), which might help protect injured cells. However, BDNF infusions during cardiac arrest in normothermic rats were not neuroprotective (Callaway et al., 2008). Thus, induction of these growth factors alone does not seem to explain the protective effects of mild hypothermia after resuscitation.

\section{HYPOTHERMIA DURING THE SECONDARY PHASE}

Mitochondrial failure is a hallmark of secondary injury evolution (Bennet et al., 2006). Thus, maintaining mitochondria intact after severe HI is crucial in promoting neuroprotection. There is compelling evidence that hypothermia started in the latent phase must be continued for $48 \mathrm{~h}$ or more to maintain improved recovery of mitochondrial membrane potential and respiration (Gong et al., 2013), and prevent cell death (Gunn and Thoresen, 2006). The precise reasons are unknown. The most likely explanation is that it is necessary to continue suppressing the programmed cell death and inflammatory pathways until normal homeostasis returns. Alternatively, it could in part reflect suppression of secondary events in this phase, including hyperperfusion, cytotoxic edema and delayed seizures. For example, selective head or whole body cooling in newborn piglets failed to provide any protection when delayed until $3 \mathrm{~h}$ after the insult and continued for only $24 \mathrm{~h}$ (Karlsson et al., 2008).

In the near-term fetal sheep, cerebral hypothermia started $5.5 \mathrm{~h}$ after ischemia and continued until $72 \mathrm{~h}$, was associated with marked extension of secondary hypoperfusion, to nearly $24 \mathrm{~h}$ after the insult (Gunn et al., 1998). We have previously shown that this hypoperfusion phase is associated with suppressed cerebral metabolism in the preterm fetal sheep (Jensen et al., 2006). Although prolonged cerebral hypoperfusion after asphyxia neonatorum has been associated with adverse clinical outcome (Elstad et al., 2011), the prolongation of reduced blood flow from cooling was associated with improved neural outcome (Gunn et al., 1998). Conversely, the subsequent onset of secondary hyperperfusion is strongly associated with injury, both in fetal sheep (Bennet et al., 2006), and in newborn infants (Elstad et al., 2011). However, cooling in the fetal sheep prevents hyperperfusion, independently of subsequent neuroprotection (Gunn et al., 1997, 1998).

Similarly, neuroprotection with cerebral cooling started 90 min after cerebral ischemia was associated with potent prevention of secondary cytotoxic edema in near-term fetal sheep (Gunn et al., 1997). Intriguingly, hypothermia started after the onset of secondary seizures ( $8.5 \mathrm{~h}$ after ischemia) also completely prevented secondary cytotoxic edema in the same paradigm, but offered no significant neuroprotection (Gunn et al., 1999). In vitro, cooling can prevent intracellular ion and water entry and the consequent osmotic cell swelling even if the ATP dependent $\mathrm{Na}^{+} / \mathrm{K}^{+}$pump is inhibited by ouabain (Zeevalk and Nicklas, 1996). These findings suggest that suppression of cell swelling is not a direct mechanism of hypothermic neuroprotection.

Clinical studies have found a reduced seizure burden during cooling of infants with hypoxic-ischemic encephalopathy (Glass et al., 2011; Srinivasakumar et al., 2013). Interestingly, despite the effects on cerebral metabolism and perfusion, and the reduction in neuronal loss, post-insult hypothermia did not significantly reduce the rate of electrographic seizures after ischemia or asphyxia in fetal sheep, but did reduce their amplitude (Gunn et al., 1998; Bennet et al., 2007a). Assuming that coupling of flow-metabolism remains intact, the reduced carotid blood flow suggests that cooling may have ameliorated the excessive local metabolic demand associated with seizure activity, which has been shown to directly mediate local neuronal death (Ingvar, 1986; Pereira De Vasconcelos et al., 2002). Treatment with MK-801, a highly potent, selective glutamate antagonist, between 6 and $24 \mathrm{~h}$ after cerebral ischemia prevented delayed post-ischemic seizures and completely suppressed fetal EEG activity (Tan et al., 1992). Surprisingly, there was no improvement in parasagittal neuronal loss, and only a modest improvement in less damaged regions such as the temporal lobe (Tan et al., 1992). These findings suggest that severe seizure activity in the secondary phase may contribute to spreading of injury from the core area of damage to more mildly affected regions, and thus anticonvulsant therapy during hypothermia might modulate outcome, although it would be unlikely to alleviate major disabilities.

\section{CLINICAL IMPLICATIONS?}

Collectively, the experimental findings described in this review strongly indicate that to achieve optimal neuroprotection, therapeutic hypothermia should be initiated as soon as possible after resuscitation, within approximately the first $6 \mathrm{~h}$ of life, should involve cooling by approximately $3-5^{\circ} \mathrm{C}$, and should be continued for approximately $48-72 \mathrm{~h}$ until resolution of the secondary phase of injury. Given that in clinical trials to date infants cooling was not started until typically $4.5-5 \mathrm{~h}$ (Edwards et al., 2010), it is extremely likely that a pragmatic focus on starting cooling earlier would substantially improve the outcomes of current clinical protocols for therapeutic hypothermia (Thoresen et al., 2013).

Beyond this, further advances are likely to come from developing complementary therapies to add to cooling. As outlined in this review, the protective mechanisms that underlie therapeutic hypothermia are multifactorial. Suppression of inflammation, intracellular signaling and programmed cell death are all important potential pathways to neuroprotection after induced hypothermia. Strategies to augment hypothermic protection may involve protecting mitochondrial function during the latent phase, for example with the natural hormone melatonin (Robertson et al., 2012). Alternatively it may be possible to actively augment neural recovery during long-term recovery after treatment with hypothermia, for example with cell therapy as suggested by preclinical models (Bennet et al., 2012).

\section{ACKNOWLEDGMENTS}

The authors' work reported in this review has been supported by the Health Research Council of New Zealand, Lottery Health Board of New Zealand, the Auckland Medical Research Foundation, and the March of Dimes Birth Defects Foundation. Mr. Guido Wassink was supported by a Auckland University Health Research Doctoral scholarship. 


\section{REFERENCES}

Askalan, R., Wang, C., Shi, H., Armstrong, E., and Yager, J. Y. (2011). The effect of postischemic hypothermia on apoptotic cell death in the neonatal rat brain. Dev. Neurosci. 33, 320-329. doi: 10.1159/000329924

Azzopardi, D., Wyatt, J. S., Cady, E. B., Delpy, D. T., Baudin, J., Stewart, A. L., et al. (1989). Prognosis of newborn infants with hypoxic-ischemic brain injury assessed by phosphorus magnetic resonance spectroscopy. Pediatr. Res. 25, 445-451. doi: 10.1203/00006450-198905000-00004

Bagenholm, R., Nilsson, U. A., Gotborg, C. W., and Kjellmer, I. (1998). Free radicals are formed in the brain of fetal sheep during reperfusion after cerebral ischemia. Pediatr. Res. 43, 271-275. doi: 10.1203/00006450-199802000-00019

Barrett, R. D., Bennet, L., Naylor, A., George, S. A., Dean, J. M., and Gunn, A. J. (2012). Effect of cerebral hypothermia and asphyxia on the subventricular zone and white matter tracts in preterm fetal sheep. Brain Res. 1469, 35-42. doi: 10.1016/j.brainres.2012.06.018

Bart, R. D., Takaoka, S., Pearlstein, R. D., Dexter, F., and Warner, D. S. (1998). Interactions between hypothermia and the latency to ischemic depolarization: implications for neuroprotection. Anesthesiology 88, 1266-1273. doi: 10.1097/00000542-199805000-00018

Baumann, E., Preston, E., Slinn, J., and Stanimirovic, D. (2009). Post-ischemic hypothermia attenuates loss of the vascular basement membrane proteins, agrin and SPARC, and the blood-brain barrier disruption after global cerebral ischemia. Brain Res. 1269, 185-197. doi: 10.1016/j.brainres.2009.02.062

Beilharz, E. J., Williams, C. E., Dragunow, M., Sirimanne, E. S., and Gluckman, P. D. (1995). Mechanisms of delayed cell death following hypoxic-ischemic injury in the immature rat: evidence for apoptosis during selective neuronal loss. Mol. Brain Res. 29, 1-14. doi: 10.1016/0169-328X(94)00217-3

Bennet, L., Booth, L., and Gunn, A. J. (2010). Potential biomarkers for hypoxicischemic encephalopathy. Semin. Fetal Neonatal Med. 15, 253-260. doi: 10.1016/j.siny.2010.05.007

Bennet, L., Dean, J. M., Wassink, G., and Gunn, A. J. (2007a). Differential effects of hypothermia on early and late epileptiform events after severe hypoxia in preterm fetal sheep. J. Neurophysiol. 97, 572-578. doi: 10.1152/jn.00957.2006

Bennet, L., Roelfsema, V., Dean, J., Wassink, G., Power, G. G., Jensen, E. C., et al. (2007b). Regulation of cytochrome oxidase redox state during umbilical cord occlusion in preterm fetal sheep. Am. J. Physiol. Regul. Integr. Comp. Physiol. 292, R1569-R1576. doi: 10.1152/ajpregu.00743.2006

Bennet, L., Roelfsema, V., George, S., Dean, J. M., Emerald, B. S., and Gunn, A. J. (2007c). The effect of cerebral hypothermia on white and grey matter injury induced by severe hypoxia in preterm fetal sheep. J. Physiol. 578, 491-506. doi: 10.1113/jphysiol.2006.119602

Bennet, L., Roelfsema, V., Pathipati, P., Quaedackers, J., and Gunn, A. J. (2006). Relationship between evolving epileptiform activity and delayed loss of mitochondrial activity after asphyxia measured by near-infrared spectroscopy in preterm fetal sheep. J. Physiol. 572, 141-154. doi: 10.1113/jphysiol.2006.105197

Bennet, L., Tan, S., Van Den Heuij, L., Derrick, M., Groenendaal, F., Van Bel, F., et al. (2012). Cell therapy for neonatal hypoxia-ischemia and cerebral palsy. Ann. Neurol. 71, 589-600. doi: 10.1002/ana.22670

Bossenmeyer-Pourie, C., Koziel, V., and Daval, J. L. (2000). Effects of hypothermia on hypoxia-induced apoptosis in cultured neurons from developing rat forebrain: comparison with preconditioning. Pediatr. Res. 47, 385-391. doi: 10.1203/00006450-200003000-00017

Brown, G. C. (1997). Nitric oxide inhibition of cytochrome oxidase and mitochondrial respiration: implications for inflammatory, neurodegenerative and ischaemic pathologies. Mol. Cell. Biochem. 174, 189-192. doi: 10.1023/A:1006800322719

Callaway, C. W., Ramos, R., Logue, E. S., Betz, A. E., Wheeler, M., and Repine, M. J. (2008). Brain-derived neurotrophic factor does not improve recovery after cardiac arrest in rats. Neurosci. Lett. 445, 103-107. doi: 10.1016/j.neulet.2008.08.019

Canevari, L., Console, A., Tendi, E. A., Clark, J. B., and Bates, T. E. (1999). Effect of postischaemic hypothermia on the mitochondrial damage induced by ischaemia and reperfusion in the gerbil. Brain Res. 817, 241-245. doi: 10.1016/S0006-8993(98)01278-5

Centers for Disease Control and Prevention (CDC). (2004). Economic costs associated with mental retardation, cerebral palsy, hearing loss, and vision impairment-United States, 2003. MMWR Morb. Mortal. Wkly. Rep. 53, 57-59. Available online at: http://www.cdc.gov/mmwr/preview/mmwrhtml/ mm5303a4.htm
Ceulemans, A. G., Zgavc, T., Kooijman, R., Hachimi-Idrissi, S., Sarre, S., and Michotte, Y. (2011). Mild hypothermia causes differential, time-dependent changes in cytokine expression and gliosis following endothelin-1-induced transient focal cerebral ischemia. J. Neuroinflammation 8 , 60. doi: 10.1186/17422094-8-60

Clawson, T. F., Vannucci, S. J., Wang, G. M., Seaman, L. B., Yang, X. L., and Lee, W. H. (1999). Hypoxia-ischemia-induced apoptotic cell death correlates with IGFI mRNA decrease in neonatal rat brain. Biol. Signals Recept. 8, 281-293. doi: $10.1159 / 000014599$

Colbourne, F., Corbett, D., Zhao, Z., Yang, J., and Buchan, A. M. (2000). Prolonged but delayed postischemic hypothermia: a long-term outcome study in the rat middle cerebral artery occlusion model. J. Cereb. Blood Flow Metab. 20, 1702-1708. doi: 10.1097/00004647-200012000-00009

Colbourne, F., Grooms, S. Y., Zukin, R. S., Buchan, A. M., and Bennett, M. V. (2003). Hypothermia rescues hippocampal CA1 neurons and attenuates downregulation of the AMPA receptor GluR2 subunit after forebrain ischemia. Proc. Natl. Acad. Sci. U.S.A. 100, 2906-2910. doi: 10.1073/pnas.2628027100

Colbourne, F., Li, H., and Buchan, A. M. (1999a). Indefatigable CAl sector neuroprotection with mild hypothermia induced 6 hours after severe forebrain ischemia in rats. J. Cereb. Blood Flow Metab. 19, 742-749. doi: 10.1097/00004647-199907000-00003

Colbourne, F., Sutherland, G. R., and Auer, R. N. (1999b). Electron microscopic evidence against apoptosis as the mechanism of neuronal death in global ischemia. J. Neurosci. 19, 4200-4210.

Cooper, C. E., and Springett, R. (1997). Measurement of cytochrome oxidase and mitochondrial energetics by near-infrared spectroscopy. Philos. Trans. R. Soc. Lond. B Biol. Sci. 352, 669-676. doi: 10.1098/rstb.1997.0048

D’Cruz, B. J., Fertig, K. C., Filiano, A. J., Hicks, S. D., Defranco, D. B., and Callaway, C. W. (2002). Hypothermic reperfusion after cardiac arrest augments brainderived neurotrophic factor activation. J. Cereb. Blood Flow Metab. 22, 843-851. doi: 10.1097/00004647-200207000-00009

Dean, J. M., George, S. A., Wassink, G., Gunn, A. J., and Bennet, L. (2006a). Suppression of post hypoxic-ischemic EEG transients with dizocilpine is associated with partial striatal protection in the preterm fetal sheep Neuropharmacology 50, 491-503. doi: 10.1016/j.neuropharm.2005.10.017

Dean, J. M., Gunn, A. J., Wassink, G., George, S., and Bennet, L. (2006b). Endogenous alpha(2)-adrenergic receptor-mediated neuroprotection after severe hypoxia in preterm fetal sheep. Neuroscience 142, 615-628. doi: 10.1016/j.neuroscience.2006.06.066

Dell'anna, E., Chen, Y., Engidawork, E., Andersson, K., Lubec, G., Luthman, J., et al. (1997). Delayed neuronal death following perinatal asphyxia in rat. Exp. Brain Res. 115, 105-115. doi: 10.1007/PL00005670

Diestel, A., Troeller, S., Billecke, N., Sauer, I. M., Berger, F., and Schmitt, K. R. (2010). Mechanisms of hypothermia-induced cell protection mediated by microglial cells in vitro. Eur. J. Neurosci. 31, 779-787. doi: 10.1111/j.14609568.2010.07128.x

Drury, P. P., Davidson, J. O., Van Den Heuij, L. G., Tan, S., Silverman, R. B., Ji, H., et al. (2013). Partial neuroprotection by nNOS inhibition during profound asphyxia in preterm fetal sheep. Exp. Neurol. 250C, 282-292. doi: 10.1016/j.expneurol.2013.10.003

Druzhyna, N. M., Musiyenko, S. I., Wilson, G. L., and Ledoux, S. P. (2005). Cytokines induce nitric oxide-mediated mtDNA damage and apoptosis in oligodendrocytes. Protective role of targeting 8-oxoguanine glycosylase to mitochondria. J. Biol. Chem. 280, 21673-21679. doi: 10.1074/jbc.M411531200

Edwards, A. D., Brocklehurst, P., Gunn, A. J., Halliday, H., Juszczak, E., Levene, M., et al. (2010). Neurological outcomes at 18 months of age after moderate hypothermia for perinatal hypoxic ischaemic encephalopathy: synthesis and meta-analysis of trial data. BMJ 340:c363. doi: 10.1136/bmj.c363

Edwards, A. D., Yue, X., Cox, P., Hope, P. L., Azzopardi, D. V., Squier, M. V., et al. (1997). Apoptosis in the brains of infants suffering intrauterine cerebral injury. Pediatr. Res. 42, 684-689. doi: 10.1203/00006450-19971100000022

Edwards, A. D., Yue, X., Squier, M. V., Thoresen, M., Cady, E. B., Penrice, J., et al. (1995). Specific inhibition of apoptosis after cerebral hypoxia-ischaemia by moderate post-insult hypothermia. Biochem. Biophys. Res. Commun. 217, 1193-1199. doi: 10.1006/bbrc.1995.2895

Elstad, M., Whitelaw, A., and Thoresen, M. (2011). Cerebral Resistance Index is less predictive in hypothermic encephalopathic newborns. Acta Paediatr. 100, 1344-1349. doi: 10.1111/j.1651-2227.2011.02327.x 
Engidawork, E., Loidl, F., Chen, Y., Kohlhauser, C., Stoeckler, S., Dell'anna, E., et al. (2001). Comparison between hypothermia and glutamate antagonism treatments on the immediate outcome of perinatal asphyxia. Exp. Brain Res. 138, 375-383. doi: 10.1007/s002210100710

Fraser, M., Bennet, L., Van Zijl, P. L., Mocatta, T. J., Williams, C. E., Gluckman, P. D., et al. (2008). Extracellular amino acids and peroxidation products in the periventricular white matter during and after cerebral ischemia in preterm fetal sheep. J. Neurochem. 105, 2214-2223. doi: 10.1111/j.1471-4159.2008.05313.x

Gehrmann, J., Banati, R. B., Wiessner, C., Hossmann, K. A., and Kreutzberg, G. W. (1995). Reactive microglia in cerebral ischaemia: an early mediator of tissue damage? Neuropathol. Appl. Neurobiol. 21, 277-289. doi: 10.1111/j.13652990.1995.tb01062.x

George, S. A., Barrett, R. D., Bennet, L., Mathai, S., Jensen, E. C., and Gunn, A. J. (2012). Nonadditive neuroprotection with early glutamate receptor blockade and delayed hypothermia after asphyxia in preterm fetal sheep. Stroke 43, 3114-3117. doi: 10.1161/STROKEAHA.112.671982

George, S. A., Bennet, L., Weaver-Mikaere, L., Fraser, M., Bouwmans, J., Mathai, S., et al. (2011). White matter protection with insulin like-growth factor 1 (IGF-1) and hypothermia is not additive after severe reversible cerebral ischemia in term fetal sheep. Dev. Neurosci. 33, 280-287. doi: 10.1159/000329923

George, S., Gunn, A. J., Westgate, J. A., Brabyn, C., Guan, J., and Bennet, L. (2004). Fetal heart rate variability and brainstem injury after asphyxia in preterm fetal sheep. Am. J. Physiol. Regul. Integr. Comp. Physiol. 287, R925-R933. doi: 10.1152/ajpregu.00263.2004

Gibson, M. E., Han, B. H., Choi, J., Knudson, C. M., Korsmeyer, S. J., Parsadanian, M., et al. (2001). BAX contributes to apoptotic-like death following neonatal hypoxia-ischemia: evidence for distinct apoptosis pathways. Mol. Med. 7, 644-655. Available online at: http://www.ncbi.nlm.nih.gov/pmc/articles/ PMC1950070/pdf/11778654.pdf

Giulian, D., and Vaca, K. (1993). Inflammatory glia mediate delayed neuronal damage after ischemia in the central nervous system. Stroke 24, I84-I90.

Glass, H. C., Nash, K. B., Bonifacio, S. L., Barkovich, A. J., Ferriero, D. M., Sullivan, J. E., et al. (2011). Seizures and magnetic resonance imaging-detected brain injury in newborns cooled for hypoxic-ischemic encephalopathy. J. Pediatr. 159, 731 e731-735 e731. doi: 10.1016/j.jpeds.2011.07.015

Goldstein, J. C., Waterhouse, N. J., Juin, P., Evan, G. I., and Green, D. R. (2000). The coordinate release of cytochrome c during apoptosis is rapid, complete and kinetically invariant. Nat. Cell Biol. 2, 156-162. doi: 10.1038/35004029

Gong, P., Hua, R., Zhang, Y., Zhao, H., Tang, Z., Mei, X., et al. (2013). Hypothermia-induced neuroprotection is associated with reduced mitochondrial membrane permeability in a swine model of cardiac arrest. J. Cereb. Blood Flow Metab. 33, 928-934. doi: 10.1038/jcbfm.2013.33

Graham, E. M., Sheldon, R. A., Flock, D. L., Ferriero, D. M., Martin, L. J., O'riordan, D. P., et al. (2004). Neonatal mice lacking functional Fas death receptors are resistant to hypoxic-ischemic brain injury. Neurobiol. Dis. 17, 89-98. doi: 10.1016/j.nbd.2004.05.007

Gressens, P., Le Verche, V., Fraser, M., Rousset, C. I., Schwendimann, L., Bennet, L., et al. (2011). Pitfalls in the quest of neuroprotectants for the perinatal brain. Dev. Neurosci. 33, 189-198. doi: 10.1159/000333109

Guan, J., Bennet, L., George, S., Wu, D., Waldvogel, H. J., Gluckman, P. D., et al. (2001). Insulin-like growth factor-1 reduces postischemic white matter injury in fetal sheep. J. Cereb. Blood Flow Metab. 21, 493-502. doi: 10.1097/00004647200105000-00003

Guillet, R., Edwards, A. D., Thoresen, M., Ferriero, D. M., Gluckman, P. D., Whitelaw, A., et al. (2012). Seven- to eight-year follow-up of the CoolCap trial of head cooling for neonatal encephalopathy. Pediatr. Res. 71, 205-209. doi: 10.1038/pr.2011.30

Gunn, A. J., Bennet, L., Gunning, M. I., Gluckman, P. D., and Gunn, T. R. (1999). Cerebral hypothermia is not neuroprotective when started after postischemic seizures in fetal sheep. Pediatr. Res. 46, 274-280. doi: 10.1203/00006450199909000-00005

Gunn, A. J., and Gluckman, P. D. (2007). Head cooling for neonatal encephalopathy: the state of the art. Clin. Obstet. Gynecol. 50, 636-651. doi: 10.1097/GRF.0b013e31811ebe68

Gunn, A. J., Gunn, T. R., De Haan, H. H., Williams, C. E., and Gluckman, P. D. (1997). Dramatic neuronal rescue with prolonged selective head cooling after ischemia in fetal lambs. J. Clin. Invest. 99, 248-256. doi: 10.1172/JCI119153

Gunn, A. J., Gunn, T. R., Gunning, M. I., Williams, C. E., and Gluckman, P. D. (1998). Neuroprotection with prolonged head cooling started before postischemic seizures in fetal sheep. Pediatrics 102, 1098-1106. doi: 10.1542/peds. 102.5 .1098

Gunn, A. J., and Thoresen, M. (2006). Hypothermic neuroprotection. NeuroRx 3, 154-169. doi: 10.1016/j.nurx.2006.01.007

Hagberg, H., Gressens, P., and Mallard, C. (2012). Inflammation during fetal and neonatal life: Implications for neurologic and neuropsychiatric disease in children and adults. Ann. Neurol. 71, 444-457. doi: 10.1002/ana.22620

Hagberg, H., Mallard, C., Rousset, C. I., and Xiaoyang, W. (2009). Apoptotic mechanisms in the immature brain: involvement of mitochondria. J. Child Neurol. 24 , 1141-1146. doi: 10.1177/0883073809338212

Hattori, H., Morin, A. M., Schwartz, P. H., Fujikawa, D. G., and Wasterlain, C. G. (1989). Posthypoxic treatment with MK-801 reduces hypoxic-ischemic damage in the neonatal rat. Neurology 39, 713-718. doi: 10.1212/WNL.39.5.713

Hu, B. R., Liu, C. L., Ouyang, Y., Blomgren, K., and Siesjo, B. K. (2000). Involvement of caspase-3 in cell death after hypoxia-ischemia declines during brain maturation. J. Cereb. Blood Flow Metab. 20, 1294-1300. doi: 10.1097/00004647200009000-00003

Ikonomidou, C., Mosinger, J. L., and Olney, J. W. (1989). Hypothermia enhances protective effect of MK-801 against hypoxic/ischemic brain damage in infant rats. Brain Res. 487, 184-187. doi: 10.1016/0006-8993(89)90956-6

Inamasu, J., Suga, S., Sato, S., Horiguchi, T., Akaji, K., Mayanagi, K., et al. (2000). Postischemic hypothermia attenuates apoptotic cell death in transient focal ischemia in rats. Acta Neurochir.Suppl. 76, 525-527. doi: 10.1007/978-3-70916346-7_110

Ingvar, M. (1986). Cerebral blood flow and metabolic rate during seizures. Relationship to epileptic brain damage. Ann. N.Y. Acad. Sci. 462, 194-206. doi: 10.1111/j.1749-6632.1986.tb51254.x

Iwata, O., Iwata, S., Bainbridge, A., De Vita, E., Matsuishi, T., Cady, E. B., et al. (2008). Supra- and sub-baseline phosphocreatine recovery in developing brain after transient hypoxia-ischaemia: relation to baseline energetics, insult severity and outcome. Brain 131, 2220-2226. doi: 10.1093/brain/awn150

Jensen, E. C., Bennet, L., Hunter, C. J., Power, G. G., and Gunn, A. J. (2006). Posthypoxic hypoperfusion is associated with suppression of cerebral metabolism and increased tissue oxygenation in near-term fetal sheep. J. Physiol. 572, 131-139. doi: 10.1113/jphysiol.2005.100768

Jensen, F. E., Wang, C., Stafstrom, C. E., Liu, Z., Geary, C., and Stevens, M. C. (1998). Acute and chronic increases in excitability in rat hippocampal slices after perinatal hypoxia In vivo. J. Neurophysiol. 79, 73-81.

Karlsson, M., Tooley, J. R., Satas, S., Hobbs, C. E., Chakkarapani, E., Stone, J., et al. (2008). Delayed hypothermia as selective head cooling or whole body cooling does not protect brain or body in newborn pig subjected to hypoxia-ischemia. Pediatr. Res. 64, 74-78. doi: 10.1203/PDR.0b013e318174efdd

Kim, J. Y., Kim, N., Yenari, M. A., and Chang, W. (2011). Mild hypothermia suppresses calcium-sensing receptor (CaSR) induction following forebrain ischemia while increasingGABA-B receptor 1 (GABA-B-R1) expression. Transl. Stroke Res. 2, 195-201. doi: 10.1007/s12975-011-0082-4

Kurinczuk, J. J., White-Koning, M., and Badawi, N. (2010). Epidemiology of neonatal encephalopathy and hypoxic-ischaemic encephalopathy. Early Hum. Dev. 86, 329-338. doi: 10.1016/j.earlhumdev.2010.05.010

Laptook, A. R., Corbett, R. J., Sterett, R., Garcia, D., and Tollefsbol, G. (1995). Quantitative relationship between brain temperature and energy utilization rate measured in vivo using $31 \mathrm{P}$ and $1 \mathrm{H}$ magnetic resonance spectroscopy. Pediatr. Res. 38, 919-925. doi: 10.1203/00006450-199512000-00015

Lawn, J. E., Cousens, S., and Zupan, J. (2005). 4 million neonatal deaths: when? Where? Why? Lancet 365, 891-900. doi: 10.1016/S0140-6736(05)71048-5

Lei, B., Adachi, N., and Arai, T. (1997). The effect of hypothermia on H2O2 production during ischemia and reperfusion: a microdialysis study in the gerbil hippocampus. Neurosci. Lett. 222, 91-94. doi: 10.1016/S0304-3940(97)13349-3

Lei, B., Tan, X., Cai, H., Xu, Q., and Guo, Q. (1994). Effect of moderate hypothermia on lipid peroxidation in canine brain tissue after cardiac arrest and resuscitation. Stroke 25, 147-152. doi: 10.1161/01.STR.25.1.147

Li, S., Zhang, Z., Xue, J., Liu, A., and Zhang, H. (2012). Cold-inducible RNA binding protein inhibits $\mathrm{H}(2) \mathrm{O}(2)$-induced apoptosis in rat cortical neurons. Brain Res. 1441, 47-52. doi: 10.1016/j.brainres.2011.12.053

Liu, L., Kim, J. Y., Koike, M. A., Yoon, Y. J., Tang, X. N., Ma, H., et al. (2008). FasL shedding is reduced by hypothermia in experimental stroke. J. Neurochem. 106, 541-550. doi: 10.1111/j.1471-4159.2008.05411.x

Lorek, A., Takei, Y., Cady, E. B., Wyatt, J. S., Penrice, J., Edwards, A. D., et al. (1994). Delayed ("secondary") cerebral energy failure after acute hypoxia-ischemia 
in the newborn piglet: continuous 48-hour studies by phosphorus magnetic resonance spectroscopy. Pediatr. Res. 36, 699-706. doi: 10.1203/00006450199412000-00003

Marlow, N., Rose, A. S., Rands, C. E., and Draper, E. S. (2005). Neuropsychological and educational problems at school age associated with neonatal encephalopathy. Arch. Dis. Child. Fetal Neonatal. Ed. 90, F380-F387. doi: 10.1136/adc.2004.067520

Martinou, J. C., and Green, D. R. (2001). Breaking the mitochondrial barrier. Nat. Rev. Mol. Cell Biol. 2, 63-67. doi: 10.1038/35048069

Mcdonald, J. W., Silverstein, F. S., and Johnston, M. V. (1987). MK-801 protects the neonatal brain from hypoxic-ischemic damage. Eur. J. Pharmacol. 140, 359-361. doi: 10.1016/0014-2999(87)90295-0

Mcintyre, S., Badawi, N., Brown, C., and Blair, E. (2011). Population casecontrol study of cerebral palsy: neonatal predictors for low-risk term singletons. Pediatrics 127, e667-e673. doi: 10.1542/peds.2010-1894

Mcmanus, T., Sadgrove, M., Pringle, A. K., Chad, J. E., and Sundstrom, L. E. (2004). Intraischaemic hypothermia reduces free radical production and protects against ischaemic insults in cultured hippocampal slices. J. Neurochem. 91, 327-336. doi: 10.1111/j.1471-4159.2004.02711.x

Meybohm, P., Gruenewald, M., Zacharowski, K. D., Albrecht, M., Lucius, R., Fosel, N., et al. (2010). Mild hypothermia alone or in combination with anesthetic post-conditioning reduces expression of inflammatory cytokines in the cerebral cortex of pigs after cardiopulmonary resuscitation. Crit. Care 14, R21. doi: $10.1186 /$ cc8879

Nagel, S., Papadakis, M., Pfleger, K., Grond-Ginsbach, C., Buchan, A. M., and Wagner, S. (2012). Microarray analysis of the global gene expression profile following hypothermia and transient focal cerebral ischemia. Neuroscience 208, 109-122. doi: 10.1016/j.neuroscience.2012. 01.048

Nagel, S., Su, Y., Horstmann, S., Heiland, S., Gardner, H., Koziol, J., et al. (2008). Minocycline and hypothermia for reperfusion injury after focal cerebral ischemia in the rat: effects on BBB breakdown and MMP expression in the acute and subacute phase. Brain Res. 1188, 198-206. doi: 10.1016/j.brainres.2007.10.052

Nakai, A., Shibazaki, Y., Taniuchi, Y., Oya, A., Asakura, H., Kuroda, S., et al. (2001). Influence of mild hypothermia on delayed mitochondrial dysfunction after transient intrauterine ischemia in the immature rat brain. Brain Res. Dev. Brain Res. 128, 1-7. doi: 10.1016/S0165-3806(01)00138-9

Nakashima, K., and Todd, M. M. (1996a). Effects of hypothermia on the rate of excitatory amino acid release after ischemic depolarization. Stroke 27, 913-918. doi: 10.1161/01.STR.27.5.913

Nakashima, K., and Todd, M. M. (1996b). Effects of hypothermia, pentobarbital, and isoflurane on postdepolarization amino acid release during complete global cerebral ischemia. Anesthesiology 85, 161-168. doi: 10.1097/00000542199607000-00022

Nijboer, C. H., Heijnen, C. J., Van Der Kooij, M. A., Zijlstra, J., Van Velthoven, C. T., Culmsee, C., et al. (2011). Targeting the p53 pathway to protect the neonatal ischemic brain. Ann. Neurol. 70, 255-264. doi: 10.1002/ana.22413

Northington, F. J., Chavez-Valdez, R., and Martin, L. J. (2011). Neuronal cell death in neonatal hypoxia-ischemia. Ann. Neurol. 69, 743-758. doi: 10.1002/ana.22419

Nurse, S., and Corbett, D. (1996). Neuroprotection after several days of mild, drug-induced hypothermia. J. Cereb. Blood Flow Metab. 16, 474-480. doi: 10.1097/00004647-199605000-00014

Ooboshi, H., Ibayashi, S., Takano, K., Sadoshima, S., Kondo, A., Uchimura, H., et al. (2000). Hypothermia inhibits ischemia-induced efflux of amino acids and neuronal damage in the hippocampus of aged rats. Brain Res. 884, 23-30. doi: 10.1016/S0006-8993(00)02861-4

Pereira De Vasconcelos, A., Ferrandon, A., and Nehlig, A. (2002). Local cerebral blood flow during lithium-pilocarpine seizures in the developing and adult rat: role of coupling between blood flow and metabolism in the genesis of neuronal damage. J. Cereb. Blood Flow Metab. 22, 196-205. doi: 10.1097/00004647200202000-00007

Polster, B. M., Robertson, C. L., Bucci, C. J., Suzuki, M., and Fiskum, G. (2003). Postnatal brain development and neural cell differentiation modulate mitochondrial Bax and BH3 peptide-induced cytochrome c release. Cell Death Differ. 10, 365-370. doi: 10.1038/sj.cdd.4401158

Preston, E., and Webster, J. (2004). A two-hour window for hypothermic modulation of early events that impact delayed opening of the rat blood-brain barrier after ischemia. Acta Neuropathol. 108, 406-412. doi: 10.1007/s00401004-0905-4

Puka-Sundvall, M., Gajkowska, B., Cholewinski, M., Blomgren, K., Lazarewicz, J. W., and Hagberg, H. (2000). Subcellular distribution of calcium and ultrastructural changes after cerebral hypoxia-ischemia in immature rats. Dev. Brain Res. 125, 31-41. doi: 10.1016/S0165-3806(00)00110-3

Ranasinghe, H. S., Scheepens, A., Sirimanne, E., Mitchell, M. D., Williams, C. E., and Fraser, M. (2012). Inhibition of MMP-9 activity following hypoxic ischemia in the developing brain using a highly specific inhibitor. Dev. Neurosci. 34, 417-427. doi: 10.1159/000343257

Rice, J. E. 3rd., Vannucci, R. C., and Brierley, J. B. (1981). The influence of immaturity on hypoxic-ischemic brain damage in the rat. Ann. Neurol. 9, 131-141. doi: 10.1002/ana.410090206

Robertson, N. J., Tan, S., Groenendaal, F., Van Bel, F., Juul, S. E., Bennet, L., et al. (2012). Which neuroprotective agents are ready for bench to bedside translation in the newborn infant? J. Pediatr. 160, 544.e544-552.e544. doi: 10.1016/j.jpeds.2011.12.052

Roelfsema, V., Bennet, L., George, S., Wu, D., Guan, J., Veerman, M., et al. (2004). The window of opportunity for cerebral hypothermia and white matter injury after cerebral ischemia in near-term fetal sheep. J. Cereb. Blood Flow Metab. 24, 877-886. doi: 10.1097/01.WCB.0000123904.17746.92

Roth, S. C., Edwards, A. D., Cady, E. B., Delpy, D. T., Wyatt, J. S., Azzopardi, D., et al. (1992). Relation between cerebral oxidative metabolism following birth asphyxia, and neurodevelopmental outcome and brain growth at one year. Dev. Med. Child Neurol. 34, 285-295. doi: 10.1111/j.1469-8749.1992. tb11432.x

Rothman, S. M., and Olney, J. W. (1995). Excitotoxicity and the NMDA receptorstill lethal after eight years. Trends Neurosci. 18, 57-58.

Rousset, C. I., Baburamani, A. A., Thornton, C., and Hagberg, H. (2012). Mitochondria and perinatal brain injury. J. Matern. Fetal Neonatal Med. 25(Suppl. 1), 35-38. doi: 10.3109/14767058.2012.66 6398

Rutherford, M., Ramenghi, L. A., Edwards, A. D., Brocklehurst, P., Halliday, H., Levene, M., et al. (2010). Assessment of brain tissue injury after moderate hypothermia in neonates with hypoxic-ischaemic encephalopathy: a nested substudy of a randomised controlled trial. Lancet Neurol. 9, 39-45. doi: 10.1016/S1474-4422(09)70295-9

Sabir, H., Scull-Brown, E., Liu, X., and Thoresen, M. (2012). Immediate hypothermia is not neuroprotective after severe hypoxia-ischemia and is deleterious when delayed by 12 hours in neonatal rats. Stroke 43, 3364-3370. doi: 10.1161/STROKEAHA.112.674481

Schmidt, K. M., D’cruz, B. J., Defranco, D. B., and Callaway, C. W. (2003). Cardiac arrest and hypothermia increase GDNF in brain. Acad. Emerg. Med. 10, 480. doi: 10.1197/aemj.10.5.480-a

Schmitt, K. R., Diestel, A., Lehnardt, S., Schwartlander, R., Lange, P. E., Berger, F., et al. (2007). Hypothermia suppresses inflammation via ERK signaling pathway in stimulated microglial cells. J. Neuroimmunol. 189, 7-16. doi: 10.1016/j.jneuroim.2007.06.010

Schug, Z. T., Gonzalvez, F., Houtkooper, R. H., Vaz, F. M., and Gottlieb, E. (2011). BID is cleaved by caspase- 8 within a native complex on the mitochondrial membrane. Cell Death Differ. 18, 538-548. doi: 10.1038/cdd.20 10.135

Scott, R. J., and Hegyi, L. (1997). Cell death in perinatal hypoxic-ischaemic brain injury. Neuropathol. Appl. Neurobiol. 23, 307-314. doi: 10.1111/j.13652990.1997.tb01300.x

Seo, J. W., Kim, J. H., Seo, M., Han, H. S., Park, J., and Suk, K. (2012). Timedependent effects of hypothermia on microglial activation and migration. J. Neuroinflammation 9, 164. doi: 10.1186/1742-2094-9-164

Shankaran, S., Barnes, P. D., Hintz, S. R., Laptook, A. R., Zaterka-Baxter, K. M., Mcdonald, S. A., et al. (2012a). Brain injury following trial of hypothermia for neonatal hypoxic-ischaemic encephalopathy. Arch. Dis. Child. Fetal Neonatal Ed. 97, F398-F404. doi: 10.1136/archdischild-2011-301524

Shankaran, S., Pappas, A., Mcdonald, S. A., Vohr, B. R., Hintz, S. R., Yolton, K., et al. (2012b). Childhood outcomes after hypothermia for neonatal encephalopathy. N. Engl. J. Med. 366, 2085-2092. doi: 10.1056/NEJMoal112066

Si, Q. S., Nakamura, Y., and Kataoka, K. (1997). Hypothermic suppression of microglial activation in culture: inhibition of cell proliferation and production of nitric oxide and superoxide. Neuroscience 81, 223-229. doi: 10.1016/S03064522(97)00172-3 
Soane, L., Siegel, Z. T., Schuh, R. A., and Fiskum, G. (2008). Postnatal developmental regulation of Bcl-2 family proteins in brain mitochondria. J. Neurosci. Res. 86, 1267-1276. doi: 10.1002/jnr.21584

Srinivasakumar, P., Zempel, J., Wallendorf, M., Lawrence, R., Inder, T., and Mathur, A. (2013). Therapeutic hypothermia in neonatal hypoxic ischemic encephalopathy: electrographic seizures and magnetic resonance imaging evidence of injury. J. Pediatr. 163, 465-470. doi: 10.1016/j.jpeds.2013.01.041

Stein, D. T., and Vannucci, R. C. (1988). Calcium accumulation during the evolution of hypoxic-ischemic brain damage in the immature rat. J. Cereb. Blood Flow Metab. 8, 834-842. doi: 10.1038/jcbfm.1988.140

Szydlowska, K., and Tymianski, M. (2010). Calcium, ischemia and excitotoxicity. Cell Calcium 47, 122-129. doi: 10.1016/j.ceca.2010.01.003

Tan, S., Zhou, F., Nielsen, V. G., Wang, Z., Gladson, C. L., and Parks, D. A. (1999). Increased injury following intermittent fetal hypoxia-reoxygenation is associated with increased free radical production in fetal rabbit brain. J. Neuropathol. Exp. Neurol. 58, 972-981. doi: 10.1097/00005072-199909000-00007

Tan, W. K., Williams, C. E., During, M. J., Mallard, C. E., Gunning, M. I., Gunn, A. J., et al. (1996). Accumulation of cytotoxins during the development of seizures and edema after hypoxic-ischemic injury in late gestation fetal sheep. Pediatr. Res. 39, 791-797. doi: 10.1203/00006450-199605000-00008

Tan, W. K., Williams, C. E., Gunn, A. J., Mallard, C. E., and Gluckman, P. D. (1992). Suppression of postischemic epileptiform activity with MK-801 improves neural outcome in fetal sheep. Ann. Neurol. 32, 677-682. doi: 10.1002/ana.410320511

Tatsumi, T., Matoba, S., Kawahara, A., Keira, N., Shiraishi, J., Akashi, K., et al. (2000). Cytokine-induced nitric oxide production inhibits mitochondrial energy production and impairs contractile function in rat cardiac myocytes. J. Am. Coll. Cardiol. 35, 1338-1346. doi: 10.1016/S0735-1097(00)00526-X

Thoresen, M., Penrice, J., Lorek, A., Cady, E. B., Wylezinska, M., Kirkbride, V., et al. (1995). Mild hypothermia after severe transient hypoxia-ischemia ameliorates delayed cerebral energy failure in the newborn piglet. Pediatr. Res. 37, 667-670. doi: 10.1203/00006450-199505000-00019

Thoresen, M., Satas, S., Puka-Sundvall, M., Whitelaw, A., Hallstrom, A., Loberg, E. M., et al. (1997). Post-hypoxic hypothermia reduces cerebrocortical release of NO and excitotoxins. Neuroreport 8, 3359-3362. doi: 10.1097/00001756199710200-00033

Thoresen, M., Tooley, J., Liu, X., Jary, S., Fleming, P., Luyt, K., et al. (2013). Time is brain: starting therapeutic hypothermia within three hours after birth improves motor outcome in asphyxiated newborns. Neonatology 104, 228-233. doi: $10.1159 / 000353948$

Tooley, J. R., Satas, S., Porter, H., Silver, I. A., and Thoresen, M. (2003). Head cooling with mild systemic hypothermia in anesthetized piglets is neuroprotective. Ann. Neurol. 53, 65-72. doi: 10.1002/ana.10402

Vannucci, R. C., Towfighi, J., and Vannucci, S. J. (2004). Secondary energy failure after cerebral hypoxia-ischemia in the immature rat. J. Cereb. Blood Flow Metab. 24, 1090-1097. doi: 10.1097/01.WCB.0000133250.03953.63

Wang, G. J., and Thayer, S. A. (1996). Sequestration of glutamate-induced $\mathrm{Ca}^{2+}$ loads by mitochondria in cultured rat hippocampal neurons. J. Neurophysiol. 76, 1611-1621.

Wang, X., Han, W., Du, X., Zhu, C., Carlsson, Y., Mallard, C., et al. (2010). Neuroprotective effect of Bax-inhibiting peptide on neonatal brain injury. Stroke 41, 2050-2055. doi: 10.1161/STROKEAHA.110.589051

Wei, M. C., Zong, W. X., Cheng, E. H., Lindsten, T., Panoutsakopoulou, V., Ross, A. J., et al. (2001). Proapoptotic BAX and BAK: a requisite gateway to mitochondrial dysfunction and death. Science 292, 727-730. doi: 10.1126/science. 1059108

Williams, C. E., Gunn, A. J., Mallard, C., and Gluckman, P. D. (1992). Outcome after ischemia in the developing sheep brain: an electroencephalographic and histological study. Ann. Neurol. 31, 14-21. doi: 10.1002/ana.4103 10104
Xiong, M., Chen, L. X., Ma, S. M., Yang, Y., and Zhou, W. H. (2013). Shortterm effects of hypothermia on axonal injury, preoligodendrocyte accumulation and oligodendrocyte myelination after hypoxia-ischemia in the hippocampus of immature rat brain. Dev. Neurosci. 35, 17-27. doi: 10.1159/000346324

Xu, L., Yenari, M. A., Steinberg, G. K., and Giffard, R. G. (2002). Mild hypothermia reduces apoptosis of mouse neurons in vitro early in the cascade. J. Cereb. Blood Flow Metab. 22, 21-28. doi: 10.1097/00004647-200201000-00003

Xu, R. X., Nakamura, T., Nagao, S., Miyamoto, O., Jin, L., Toyoshima, T., et al. (1998). Specific inhibition of apoptosis after cold-induced brain injury by moderate postinjury hypothermia. Neurosurgery 43, 107-114. doi: 10.1097/00006123-199807000-00070

Yenari, M. A., and Han, H. S. (2006). Influence of hypothermia on post-ischemic inflammation: role of nuclear factor kappa B (NFkappaB). Neurochem. Int. 49, 164-169. doi: 10.1016/j.neuint.2006.03.016

Yenari, M. A., Iwayama, S., Cheng, D., Sun, G. H., Fujimura, M., Morita-Fujimura, Y., et al. (2002). Mild hypothermia attenuates cytochrome $\mathrm{C}$ release but does not alter Bcl -2 expression or caspase activation after experimental stroke. J. Cereb. Blood Flow Metab. 22, 29-38. doi: 10.1097/00004647-200201000-00004

Zeevalk, G. D., and Nicklas, W. J. (1996). Hypothermia and metabolic stress: narrowing the cellular site of early neuroprotection. J. Pharmacol. Exp. Ther. 279, 332-339.

Zgavc, T., De Geyter, D., Ceulemans, A. G., Stoop, W., Hachimi-Idrissi, S., Michotte, Y., et al. (2013). Mild hypothermia reduces activated caspase-3 up to 1 week after a focal cerebral ischemia induced by endothelin-1 in rats. Brain Res. 1501, 81-88. doi: 10.1016/j.brainres.2013.01.034

Zhang, H., Xu, G., Zhang, J., Murong, S., Mei, Y., and Tong, E. (2010). Mild hypothermia reduces ischemic neuron death via altering the expression of p53 and bcl-2. Neurol. Res. 32, 384-389. doi: 10.1179/016164110X12670144526228

Zhao, H., Yenari, M. A., Cheng, D., Sapolsky, R. M., and Steinberg, G. K. (2005). Biphasic cytochrome $\mathrm{c}$ release after transient global ischemia and its inhibition by hypothermia. J. Cereb. Blood Flow Metab. 25, 1119-1129. doi: 10.1038/sj.jcbfm.9600111

Zhao, H., Yenari, M. A., Sapolsky, R. M., and Steinberg, G. K. (2004). Mild postischemic hypothermia prolongs the time window for gene therapy by inhibiting cytochrome C release. Stroke 35, 572-577. doi: 10.1161/01.STR.0000110787.42083.58

Zhu, C., Wang, X., Xu, F., Bahr, B. A., Shibata, M., Uchiyama, Y., et al. (2005). The influence of age on apoptotic and other mechanisms of cell death after cerebral hypoxia-ischemia. Cell Death Differ. 12, 162-176. doi: 10.1038/sj.cdd.4401545

Zipfel, G. J., Babcock, D. J., Lee, J. M., and Choi, D. W. (2000). Neuronal apoptosis after CNS injury: the roles of glutamate and calcium. J. Neurotrauma 17, 857-869. doi: 10.1089/neu.2000.17.857

Conflict of Interest Statement: The authors declare that the research was conducted in the absence of any commercial or financial relationships that could be construed as a potential conflict of interest.

Received: 19 October 2013; paper pending published: 02 December 2013; accepted: 12 February 2014; published online: 27 February 2014.

Citation: Wassink G, Gunn ER, Drury PP, Bennet L and Gunn AJ (2014) The mechanisms and treatment of asphyxial encephalopathy. Front. Neurosci. 8:40. doi: 10.3389/ fnins.2014.00040

This article was submitted to Systems Biology, a section of the journal Frontiers in Neuroscience.

Copyright (C) 2014 Wassink, Gunn, Drury, Bennet and Gunn. This is an openaccess article distributed under the terms of the Creative Commons Attribution License (CC BY). The use, distribution or reproduction in other forums is permitted, provided the original author(s) or licensor are credited and that the original publication in this journal is cited, in accordance with accepted academic practice. No use, distribution or reproduction is permitted which does not comply with these terms. 